06

\title{
Крейзы в плазмомодифицированных полимерных материалах
}

\author{
(C) М.А. Курбанов, ${ }^{1}$ И.С. Рамазанова, ${ }^{1}$ В.А. Гольдаде, ${ }^{2,3}$ А.Ф. Нуралиев, ${ }^{1}$ Ф.Ф. Яхяев, ${ }^{1}$ З.А. Дадашов, ${ }^{1}$ \\ Г.Х. Гусейнова, ${ }^{1}$ Б.Г. Худаяров ${ }^{1}$ \\ ${ }^{1}$ Институт фризики НАН Азербайджана, \\ Az-1143 Баку, Азербайджан \\ ${ }^{2}$ Институт механики металлополимерных систем им. В.А. Белого НАН Беларуси, \\ 246050 Гомель, Беларусь \\ ${ }^{3}$ Гомельский государственный университет им. Франциска Скорины, \\ 246019 Гомель, Беларусь \\ e-mail: mKurbanov@physics.ab.az
}

Поступило в Редакцию 3 октября 2019 г.

В окончательной редакции 3 октября 2019 г.

Принято к публикации 16 декабря 2019 г.

Изложены результаты исследования по формированию крейзовых центров в плазмомодифицированных полимерах. Показано, что в результате плазменной модификации происходят процессы окисления, деструкции и сшивания полимера, в результате которых создаются условия для образования крейзовых центров и, следовательно, крейзов.

Ключевые слова: крейзы, плазмомодифицированные полимеры, плазма электрического разряда, барьерный разряд, газовые включения.

DOI: 10.21883/JTF.2020.06.49286.324-19

\section{Введение}

Ранее нами было показано, что с использованием плазмы электрического разряда можно создать в полимерах центры крейзообразования [1]. Были предложены методики плазменной модификации полимеров и оптимизирована технология получения центров крейзообразования, изучено влияние внешних факторов (амплитуда электрического напряжения, время воздействия, толщина исследуемой пленки и воздушного зазора, где возникал электрический разряд) [1-4].

Однако до сих пор не изучен механизм формирования крейзовых центров в условиях действия плазмы электрического разряда.

Цель настоящей работы - изучение особенностей формирования крейзовых центров в полиэтилене, модифицированном плазмой электрического разряда.

\section{Методика эксперимента}

Методика модифицирования полимерной пленки с применением плазмы электрического разряда в воздушном зазоре, ограниченном диэлектрическими барьерами, подробно описана нами в работах $[1,5,6]$. Ориентационную вытяжку образцов осуществляли в специальной ячейке, описанной нами в работе [1].

В качестве исследуемых образцов были использованы пленки из полиэтилена (ПЭ) длиной $30 \mathrm{~mm}$, шириной $15.5 \mathrm{~mm}$ и толщиной $75 \mu \mathrm{m}$. Величину эффективной пористости вычисляли по методике, приведенной в работе [7].
Пористость в эффективном объеме пленок формировали при следующих технологических режимах:

- процесс растяжения проводили в среде атмосферы;

- скорость растяжения составляла $2.5 \mathrm{~mm} / \mathrm{min}$;

- объем образца определяли через каждые 35\% деформации, и это продолжалось до достижения деформации $210 \%(35,70,105,140,175,210 \%)$.

Полученные экспериментальные результаты являются средним значением из 10-11 опытов.

\section{Экспериментальные результаты и их обсуждение}

Результаты исследования позволяют предположить, что в условиях плазмы электрического разряда происходит предпочтительно сшивание полимера вдоль оси плазменного канала.

На рис. 1 и 2 приведены структурные изменения полимера в условиях действия плазмы электрического разряда $[5,8]$.

Как видно из рис. 2, после действия частичного разряда в воздухе ПЭ интенсивно окисляется и это сопровождается появлением новых полос поглощения, из которых наиболее выраженными являются полосы при $3400-3200 \mathrm{~cm}^{-1}$ (ОН-группы), $1750-1720 \mathrm{~cm}^{-1}$ (C=Oгруппы), $1210-1180 \mathrm{~cm}^{-1}$ (-C-O-C-группы).

Изменение ИК-спектра ПЭ под действием разрядов свидетельствует об одновременном протекании в полимере двух конкурирующих процессов: деструкции полимерных цепей и их сшивании (образование кислородных мостиков). 


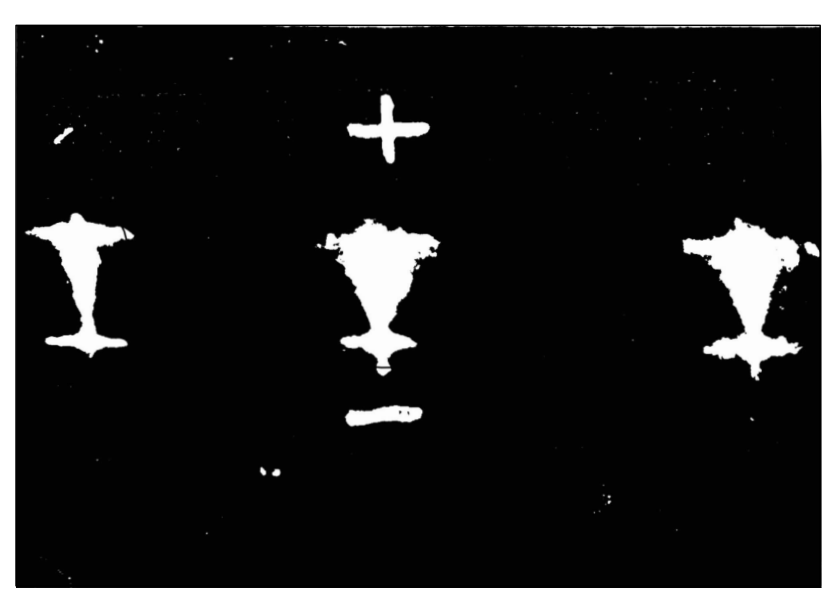

Рис. 1. Оптическая картина развития плазменного канала разряда в воздушном зазоре, ограниченном диэлектрическими барьерами.

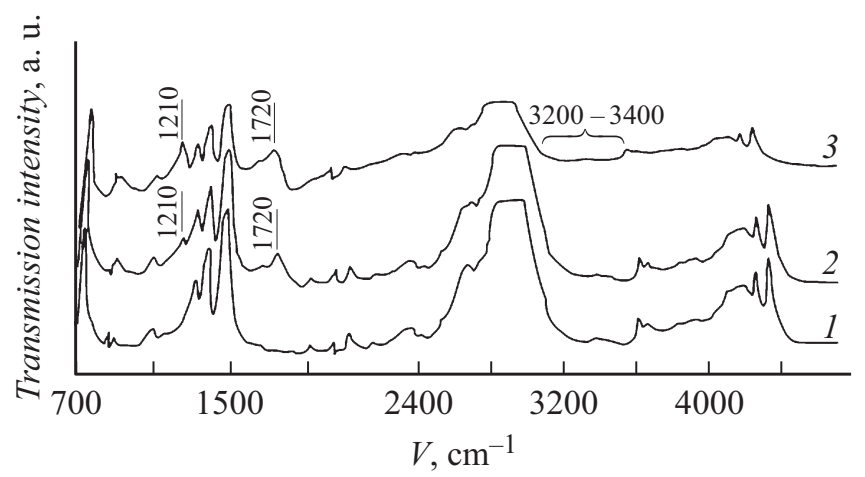

Рис. 2. ИК-спектры пленки ПЭ после действия частичных разрядов (ЧР) при различных величинах приложенного напряжения $(U): 1-$ исходный образец; $2-U=12 \mathrm{kV}$. eff; $3-$ $U=18 \mathrm{kV}$. eff. Толщина воздушного зазора $d=2 \mathrm{~mm}$, время выдержки пленок после обработки $t=20 \mathrm{~h}$.

На рис. 3 показана зависимость эффективной активной пористости $(W)$ от величины деформации (\%) исходного и плазмомодифицированного полиэтилена $[9,10]$.

Видно, что величина эффективной объемной пористости плазмомодифицированного ПЭ гораздо больше, чем исходного. Причина возникновения этого эффекта, повидимому, связана с физико-химическими изменениями структуры ПЭ в условиях действия плазмы электрического разряда.

На рис. 4 видно, что сравнительное изменение ширины плазмомодифицированных и исходных образцов ПЭ практически одинаково.

В то же время изменение толщины образцов плазмомодифицированного ПЭ несколько меньше, чем у исходных образцов (рис. 5).

Причиной этого эффекта, по нашему мнению, является возникновение $\mathrm{C}-\mathrm{O}-\mathrm{C}$-мостиков между макромолекулами, препятствующих изменению толщины образцов и, следовательно, увеличению эффективной объемной пористости.

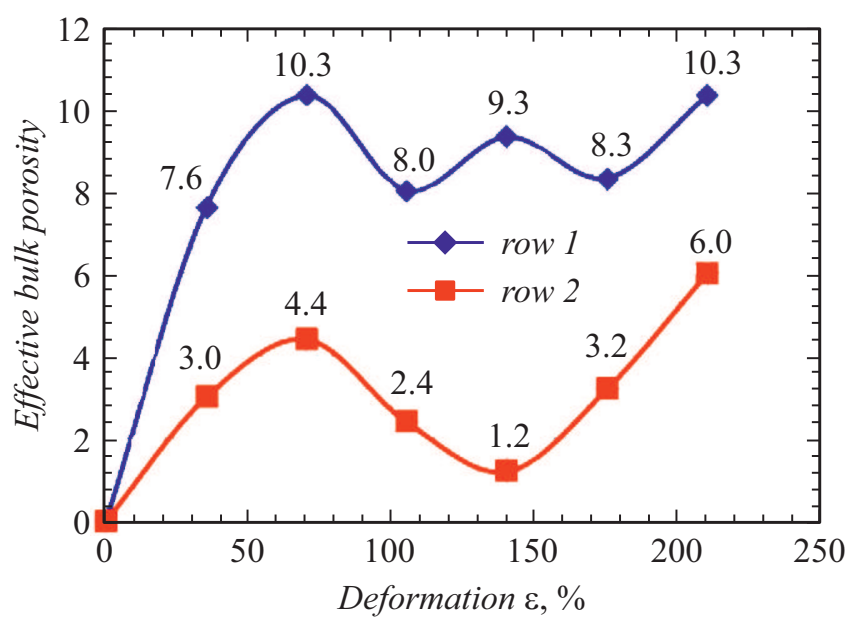

Рис. 3. Зависимость эффективной активной пористости $(\mathrm{W})$ ПЭ от величины деформации (\%). 1 - после плазменной обработки; 2 - без предварительной плазменной обработки.

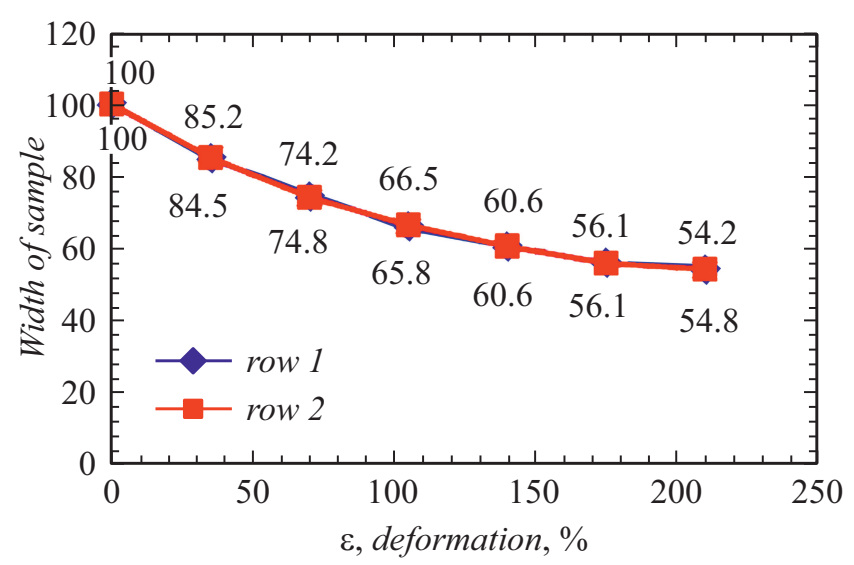

Рис. 4. Изменение ширины образцов в процессе деформации.

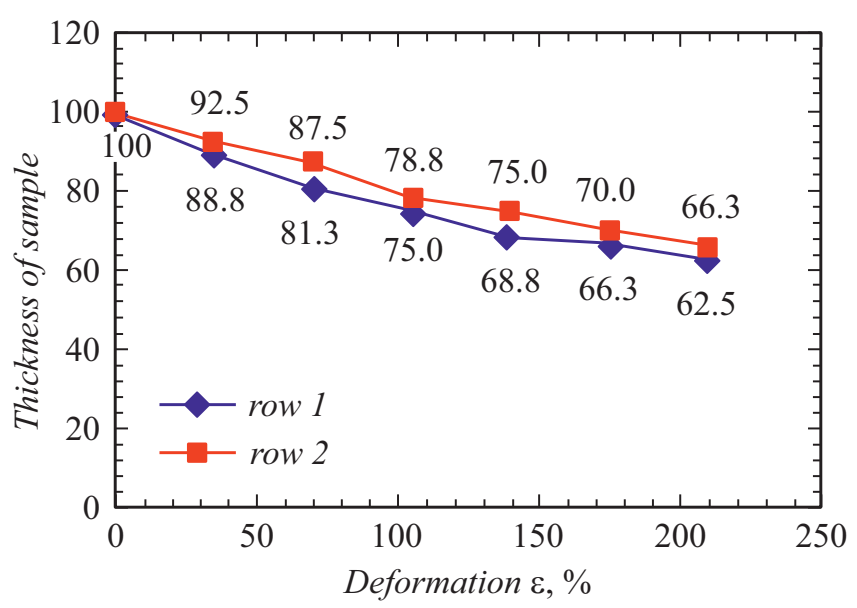

Рис. 5. Изменение толщины образцов в процессе деформации. 


\section{Заключение}

Плазменная модификация полиэтилена приводит к увеличению эффективной объемной пористости при крейзообразовании за счет формирования $\mathrm{C}-\mathrm{O}-\mathrm{C}$-мостиков между макромолекулами по направлению развития плазменного канала.

\section{Финансирование работы}

Работа выполнена при финансовой поддержке Фонда развития науки при президенте Азербайджанской республики (грант № EİF-BGM-2BRFTF-1-2012/2013) и Белорусского республиканского фонда фундаментальных исследований (грант № Т13АЗ-028).

\section{Конфликт интересов}

Авторы заявляют, что у них нет конфликта интересов.

\section{Список литературы}

[1] Курбанов М.А., Гольдаде В.А., Зотов С.В., Рамазанова И.С., Нуралиев А.Ф., Яхяев Ф.Ф., Юсифова У.В., Худаяров Б.Г. // ЖТФ. 2018. Т. 88. Вып. 7. С. 995-999.

[2] Гусев А.И. Наноматериалы, структуры и технологии. М.: Физматлит, 2009. 414 с.

[3] Помогайло А.Д., Розенберг А.С., Уфлянд И.Е. Наночастицы металлов в полимерах. М.: Химия, 2000. 672 с.

[4] Чвалун С.Н. // Полимерные нанокомпозиты. Природа. 2000. № 7. C. 22-30.

[5] Курбанов М.А. Автореф. канд. дис. Электрический разряд в воздушном зазоре, ограниченном диэлектриками. Баку, 1974. $153 \mathrm{c}$

[6] Лунин В.В., Попович М.П., Ткаченко С.Н. Физическая химия озона. М.: Изд-во МГУ, 1998.

[7] Никонорова Н.И., Трофимчук Е.С., Семенова Е.В., Волынский А.Л., Бакеев Н.Ф. // ВМС. Серия А. 2000. Т. 42. № 8. C. $1298-1306$.

[8] Багиров М.А., Курбанов М.А., Шкилев А.В. // ЖТФ. 1971. Т. 41. Вып. 6. С. 25.

[9] Волынский А.А., Бакеев Н.Ф. Структурная самоорганизация аморфных полимеров. М.: Физматлит, 2005. 232 с.

[10] Гольдаде В.А., Зотов С.В., Овчинников К.В., Курбанов М.А., Байрамов А.А., Нуралиев А.Ф. // Материалы, технологии, инструменты. 2015. Т. 20. № 1. С. 82-86. 